\title{
SEMBLANZA DE UN MAESTRO Y UN AMIGO
}

\author{
Antonio Rey Hazas \\ Universidad Autónoma de Madrid
}

Miguel Ángel Pérez Priego llegó a la Universidad Autónoma de Madrid en el curso 1971-72. Lo recuerdo muy bien. Era entonces un joven profesor sin apenas experiencia, que había estudiado en la Complutense, a quien Juan Manuel Rozas apreciaba mucho, rescató de la docencia que impartía en un colegio de Tarancón y, recién llegado, le asignó un curso monográfico nada fácil, por aquel entonces, sobre teatro del siglo XVI, del que fuimos alumnos y disfrutamos mis compañeros y yo. Pronto quedamos impresionados, porque para nosotros Juan del Encina, Torres Naharro y compañía eran unos desconocidos, a pesar de que ya estábamos en cuarto curso. Jesús Cañas y yo hicimos entonces, bajo su dirección, un trabajo sobre las danzas de la muerte que aún no hemos olvidado. Las clases de Miguel Ángel, siempre claras, rigurosas y ordenadas, nos descubrieron un mundo nuevo y coherente, a pesar de que la materia estaba aún en ciernes. Desde entonces, le tengo, como todos sus alumnos, un profundo respeto. Después, fuimos compañeros en la UAM y, poco a poco, nos hicimos amigos. Por eso puedo dar fe de que ha sido y sigue siendo un maestro ejemplar y un amigo entrañable; merecedor, por tanto, de un homenaje como éste sin duda ninguna.

Ya como compañero y amigo, estuve a su lado en algunos lances de su carrera universitaria, es decir, en sus oposiciones. Sacó la plaza de Profesor Adjunto Numerario de Literatura Española en 1979, y decidió establecerse en la Universidad de Extremadura, donde se había trasladado poco antes Juan Manuel Rozas como Catedrático de Literatura. En Cáceres, pues, residió con su familia desde 1979 hasta 1983. Por las mismas fechas se trasladaba también allí Jesús Cañas, que se estableció ya definitivamente en la universidad extremeña.

Miguel Ángel, no obstante, añoraba un espacio más abierto y cosmopolita, con las facilidades investigadoras que ofrecía la Biblioteca Nacional, el archivo Histórico o el CSIC para los que residían en la capital de España. Decidió entonces presentarse a otra 
Oposición, con plaza en Madrid, que además se ajustaba a su perfil docente e investigador como anillo al dedo, pues se trataba de la Cátedra de Historia de la Literatura Española de la Edad Media de la UNED. Ganó la plaza brillante y merecidamente en 1983, como puedo atestiguar en persona, porque estuve a su lado esos días, siempre duros, y ocupó la cátedra desde entonces hasta el día de hoy con toda justicia. De modo que puede decirse en rigor que ha ejercido (y ejerce) la mayor y mejor parte de su carrera en la UNED de Madrid; aunque abierto siempre, obvio es decirlo, a la perspectiva más amplia del hispanismo internacional, que le ha llevado participar en los seminarios y congresos más importantes de nuestras letras, y a realizar numerosas estancias de trabajo en universidades diversas de todo el mundo.

Es también interesante anotar su vocación filológica plena, pues no separaba, al menos en un primer momento, la comunidad que forman lo lingüístico y lo literario, como prueba el hecho de que leyera su Memoria de Licenciatura en la Complutense sobre la Aportación al estudio de la gramática de la Edad de Oro: Nebrija y su 'Gramática castellana', en marzo de 1970, y cuatro años más tarde la Tesis Doctoral sobre El teatro de Diego Sánchez de Badajoz en la Universidad Autónoma de Madrid. Y aunque finalmente se decantó por los estudios literarios, como es sabido, no es menos cierto que la perspectiva integradora, la mirada filológica amplia le ha acompañado siempre.

Fruto de tan larga y constante labor, de trabajo tan gustoso, de vocación tan clara y duradera, en suma, es una de las más brillantes y fructíferas carreras de nuestro hispanismo, con no menos de 42 libros, 138 artículos, 40 trabajos para diferentes Bibliografías e Historias de la Literatura Española, 213 conferencias y 107 participaciones en distintos congresos científicos, sobre una serie larga de temas que han llenado horas y horas de trabajo constante y deseado. Me refiero al teatro español del siglo XVI, en general, por una parte, con los nombres reiterados, por motivos indagadores diferentes, de Juan del Encina, Bartolomé Torres Naharro, Diego Sánchez de Badajoz, Lucas Fernández, Gil Vicente, etc., a La Celestina y a las comedias celestinescas, por otra; al Códice de autos viejos, al teatro religioso, y a todos los problemas teatrales del XVI, sin excluir a Cervantes. Ello aparte, la literatura medieval constituye el otro gran objeto de sus investigaciones, con estudios decisivos y ediciones ejemplares del Marqués de Santillana, Juan de Mena, Jorge Manrique, el Príncipe don Juan, los libros de viajes, la poesía femenina medieval, el Romance del Prisionero, los autores teatrales extremeños, los espejos de príncipes, la Biblia, la poética de la muerte, y un largo etcétera. En tercer lugar, finalmente, ha dedicado sus esfuerzos al estudio de los problemas que afectan a la edición filológica de los textos literarios, pues no en vano algunos de sus primeros trabajos fueron depuradas y sólidas ediciones de Juan de Mena, el Marqués de Santillana y Diego Sánchez de Badajoz. Simplemente recordaré La edición de textos. $2^{a}$ edición ampliada y actualizada, Madrid, Editorial Síntesis, 2011.

Ello aparte, Miguel Ángel Pérez Priego es un catedrático dedicado por entero a la enseñanza y a la dirección de trabajos de investigación, como demuestran las once Tesinas, ocho DEAS y 11 tesis Doctorales que ha dirigido: compromiso avalado por sus diversos proyectos de investigación, que se ve acentuado aún más por el ejercicio de los enojosos cargos académicos universitarios, ante los que tampoco ha escurrido el bulto, pues ha sido Vicerrector de la UNED en tres ocasiones, Director del Departamento de Literatura Española de la UNED en otras tres ocasiones, además de Director del centro 
de Cuenca de la UIMP, evaluador de proyectos oficiales de investigación en siete ocasiones, miembro de varias asociaciones científicas, director de la Revista Epos, y miembro del consejo de redacción o asesor de otras nueve revistas científicas de reconocido prestigio, como la Revista de Filología Española, la Revista de Literatura, Celestinesca, la Revista de Literatura Medieval o el Anuario de Estudios Filológicos. Es miembro fundador y colaborador, asimismo, de diversas asociaciones científicas, como la Sociedad Española de Literatura General y Comparada, la Asociación Internacional de Hispanistas o la Asociación Hispánica de Literatura Medieval, de la que ha sido Presidente, sin olvidar su calidad de miembro de distintos jurados de premios literarios, en los que alguna vez ha sido presidente.

En suma, una carrera amplia, completa, ejemplar, de exclusiva dedicación en todos los órdenes de la actividad académica, investigadora y docente de la Universidad, pues como dice una reseña que le dedicó la Revista de Libros: «por lo demás, tan sólo queda reconocer el rigor profesional y la honradez características del profesor Pérez Priego, que ha medido fuerzas, y siempre con excelentes resultados, en los terrenos literarios más variados».

No quiero acabar estas palabras sin hablar, aunque sea breve y pudorosamente, del amigo leal y generoso, siempre dispuesto a ayudar a los suyos, del amigo de verdad, y lo hago porque no se trata solo de una cuestión personal mía, sino que afecta también a su condición de maestro ejemplar, dado que el grupo de amigos que formamos hoy unos cuantos compañeros de curso (Jesús Cañas, Juan María Marín, Carmen Vaquero y Guillermo Hernández) todos profesores, incluye a Miguel Ángel Pérez Priego: no hay mejor prueba de que sigue siendo para todos nosotros maestro y amigo.

A esa admiración, tan amplia, se une la mía, muy grande: enorme admiración al profesor y compañero del alma, que con toda justicia y merecimiento recibe este homenaje. 
